\title{
22
}

\section{Defining Social-Ecological Systems in South-West Bangladesh}

\author{
Helen Adams, W. Neil Adger, Munir Ahmed, \\ Hamidul Huq, Rezaur Rahman, and Mashfiqus Salehin
}

\subsection{Introduction}

Deltas are diverse environments with spatially and temporally variable ecosystem services (Barbier et al. 2011). This chapter argues that different parts of the delta can be identified as distinct social-ecological systems. In doing so it proposes that recognising these distinct systems is crucial to understanding the persistence of poverty in natural resource dependent communities. In effect, the social mechanisms that have evolved to manage and govern access to diverse bundles of ecosystem services are distinctive and associated with different land uses (Rodriguez et al. 2006).

H. Adams $(\bowtie)$

Department of Geography, King's College London, London, UK

W. Neil Adger

Geography, College of Life and Environmental Sciences,

University of Exeter, Exeter, UK

M. Ahmed

TARA, Dhaka, Bangladesh

(C) The Author(s) 2018

R. J. Nicholls et al. (eds.), Ecosystem Services for Well-Being in Deltas,

https://doi.org/10.1007/978-3-319-71093-8_22 
Ecosystem services are co-produced in bundles in different socialecological systems. A social-ecological system is the amalgamation of physical, ecological, and social phenomena into a set of recognisable and distinct systems of interaction. Social-ecological systems theories have a long and varied intellectual history, drawing on ideas of hybrid environments, human ecology, and cultural geography. Social-ecological systems as an analytical framework emphasise the interdependent nature of the human and ecological systems (Cote and Nightingale 2012).

The chapter describes the social-ecological systems (SESs) within the study area and how they have been identified and characterised. The first section shows how social-ecological systems were integrated as a guiding principle through the project. The second section presents the results of analysis of the ways in which social systems differ according to the ecological system to form distinct sub-systems of the delta. The chapter concludes by summarising some of the key findings on the relationship between poverty reduction and ecosystem services revealed through a systems perspective.

\subsection{Social-Ecological Systems as an Analytical Framework}

Managing natural resources, promoting sustainability, and enhancing human well-being require knowledge of populations, resources, and institutions within distinct social-ecological systems. Many studies have highlighted the benefits of understanding social-ecological interactions to promote sustainable management. Analysis of landscape change in Mediterranean Spain, for example, required modelling of both the intensity of

\section{H. Huq}

Institute of Livelihood Studies, Bangladesh University of Engineering and Technology, Dhaka, Bangladesh

R. Rahman • M. Salehin Institute of Water and Flood Management, Bangladesh University of Engineering and Technology, Dhaka, Bangladesh 
agriculture and the socio-economic context in which it was implemented (De Aranzabal et al. 2008). In the marine sector, fisheries management progressed from species-based to ecosystem-based approaches that embedded humans and their associated cultural values and different management practices within the ecosystem (Levin et al. 2009).

Social-ecological perspectives are particularly suited to incorporating diverse forms of lay and scientific knowledge in natural resource management (Hill et al. 2012), co-management practices (Cinner et al. 2012), common pool resources (Nagendra and Ostrom 2014), and governance issues (Karpouzoglou et al. 2016). As such, studies have applied system approaches to better manage and conserve ecosystem services, rather than explicitly seeking to design interventions with social goals such as alleviation of poverty. However, one major and common insight from this field which is relevant for this research is that social institutions are directly affected by the underlying characteristics of the natural resource base, including the resource fluctuations, variability, and divisibility (Ostrom 1990).

Many social mechanisms employed by poor populations to access natural resources are specific to that particular resource. In capture fisheries, for example, loans to buy equipment are paid back as a proportion of the catch because of the variable and unpredictable nature of catches and thus income (Allison and Ellis 2001). Systems of sharecropping, where landowners take significant proportions of agricultural outputs as rents, emerge as a mechanism in agricultural areas dominated by private land ownership, surplus labour, and insecure livelihoods (Wood 2003). Thus, mechanisms of rent capture in agriculture and fisheries are adapted to the specific characteristics of the bundle of ecosystem services but have a similar outcome of systematically extracting surplus value away from the poorest.

\subsection{Methodology}

Social-ecological systems are identified as articulated and experienced by those engaged in resource use across the study area. Categorisation was based on data generated using open-ended questions focussed on social factors that influence the ability of ecosystem services to produce well-being 
for the poor through livelihoods, environment, and perceptions of causal mechanisms (described in Chap. 1). Other studies have used this method for exploratory analyses of this type: respondents converge on issues of multiple causation, threshold effects, and the social dynamics and processes by which social and ecological dimensions of their lives and livelihoods are constructed (e.g. Davis 2009; Crane 2010; Fabinyi et al. 2014).

Data from 70 households purposefully sampled across the dominant land cover types of the delta region was collected between September 2012 and May 2013. Effort was made to include geographically remote areas, diverse administrative districts, different land uses, and livelihood systems in households with a range of wealth statuses. The data are available in open-access form as notes and transcripts of the interviews (see Adams and Adger 2016 to access Reshare depository). Interviews were carried out in Bengali and lasted from between $30 \mathrm{~min}$ utes and one hour.

Analysis of the data suggests seven distinct SESs across the study area: irrigated and rain-fed agriculture, brackish and freshwater aquaculture, char-dominated (eroding islands) areas, areas that are dependent on the Sundarbans mangrove forest, and coastal areas with easy access to offshore fisheries. The distribution of these SESs is shown in Fig. 22.1. The majority of the study area is dedicated to crop cultivation (63 percent), predominantly rice, and the Sundarbans mangrove forest, which constitutes almost a third of the land area (29 percent). Eight per cent of the land area is dedicated to freshwater prawn, brackish shrimp, and white fish aquaculture while waterways and wetlands compose around one percent. Thus, the SESs defined can correspond directly to the dominant land use (agriculture and aquaculture) or defined by proximity to a key geographical feature (Sundarbans dependence, char areas and offshore fisheries). For an examination of the ecological characteristics of these systems, please see Chaps. 21, 24, 25, and 26 and Adams et al. (2013).

Once defined, the SESs are identified and mapped using satellite imagery and GIS analysis (see Adams et al. 2016 for a full description of this process). The SESs form the basis of analysis of the ecosystem services throughout this research highlighting the diversity of delta 


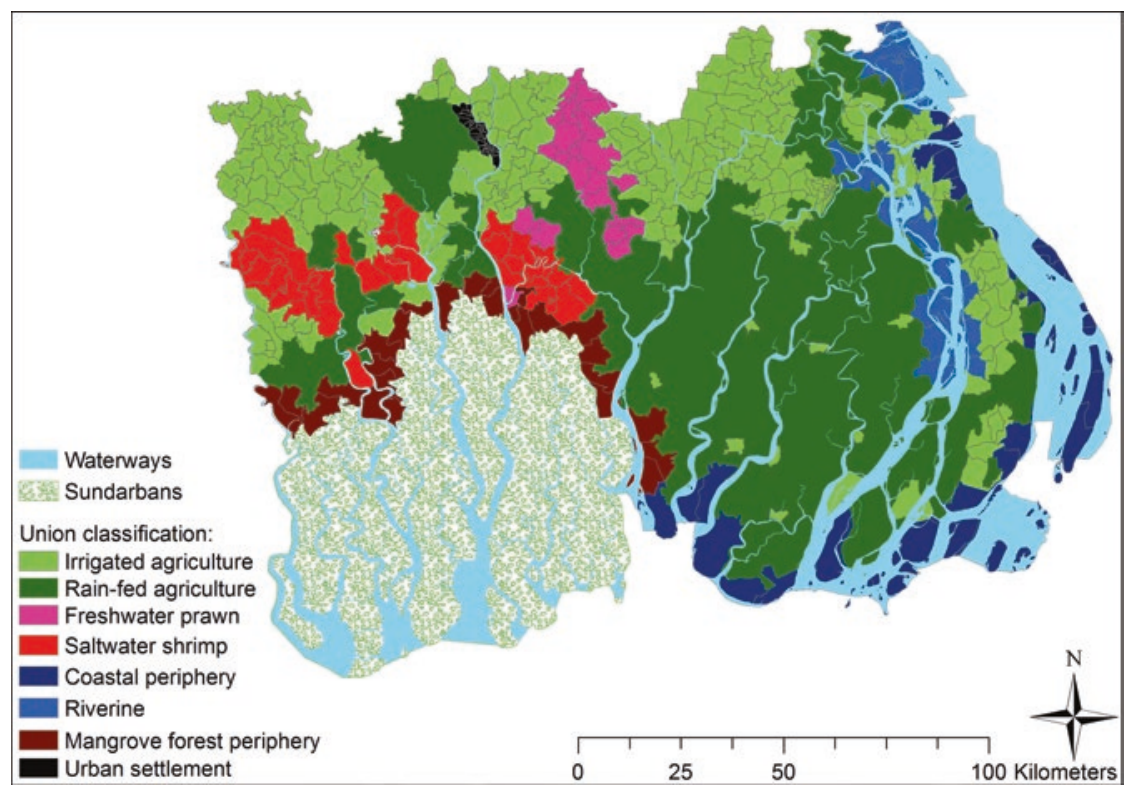

Fig. 22.1 Distribution of social-ecological systems based on survey information in the study area

environments and social trajectories across the delta region. The systems are used, for example, to analyse the influence of environmental conditions on the incidence of poverty (see Chap. 1) and form the first-level stratification of the household survey (see Chap. 23 and Adams et al. 2016). The integrated modelling approach also takes into account these different system dynamics through incorporation of the household survey data (see Chap. 28).

The remainder of this chapter presents some initial results highlighting some of the causal mechanisms linking ecosystem services and poverty in the study area and how these vary between SESs. These themes are summarised in Table 22.1, which also provides some summary statistics of the respondents. Numbers cited in brackets throughout this chapter correspond to the metadata file that accompanies the transcripts in the online database. ${ }^{1}$ 


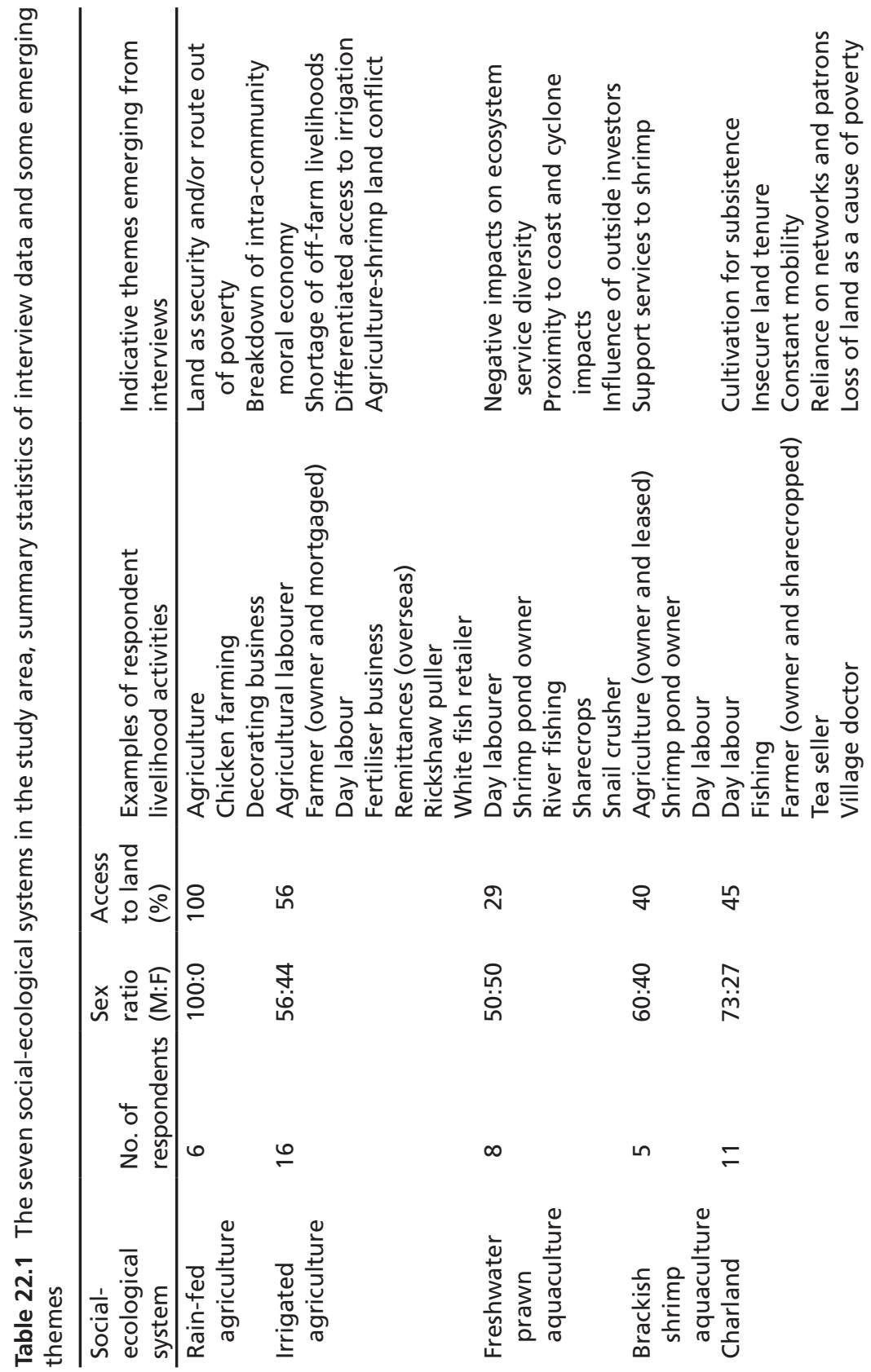



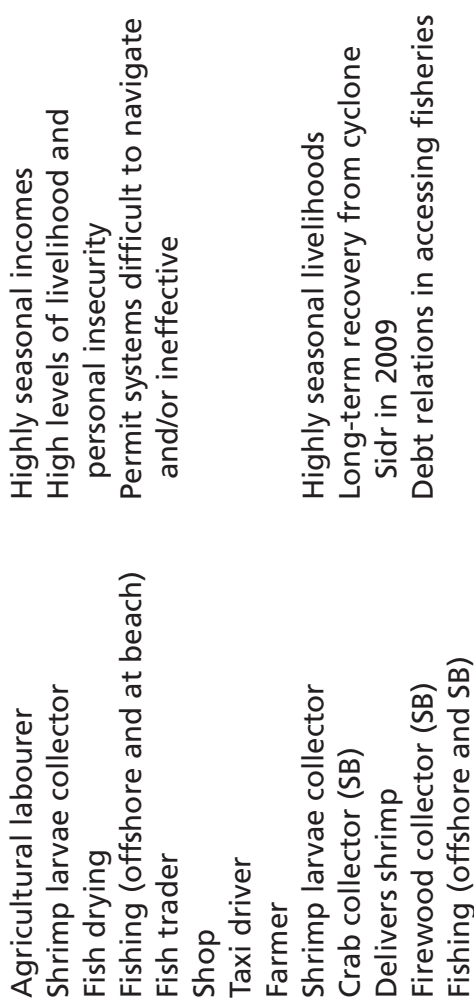

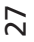

N

นึ่

ํํํ

으

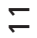

जิ

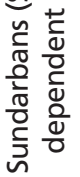

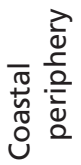




\subsection{Poverty Ecosystem Service Dynamics by Social-Ecological System}

\subsubsection{Agriculture}

In agricultural regions, two distinct SESs emerged from the interviews based on the presence or absence of irrigation infrastructure. These two systems were kept analytically separate because (i) the cost of, and access to, irrigation serves to deepen inequalities between the landed and landless, (ii) multiple cropping seasons impact on the value of produce, labour opportunities, and associated mobility, (iii) each system has a differentiated vulnerability to external pressures such as fluctuating market prices and climate change (e.g. through an ability to withstand drought or alternate between crops), and (iv) the geographic location; irrigated areas tended to be those in direct land conflict with brackish shrimp cultivation. However, some common themes emerged across interviews in both types of agricultural zone. These include access to land for food security and/or route out of poverty, breakdown of intra-community moral economy in rural villages, and a shortage of off-farm livelihoods for the large landless population.

Large landowners interviewed had leveraged their assets to start profitable business activities such as supplying organic fertiliser, painting and decorating, intensive chicken rearing, educate their families so that they could take up professional jobs, or fund international labour migration with resulting remittances. This supports similar findings from Bangladesh (Tourfique 2002). However, there is another kind of landowner, constrained by the status in society conferred by land ownership but lacking sufficient assets to access profitable off-farm activities: "Being part of the middle class society has closed the path of asking help from someone. My father was elected member [local politician] twice, this has given us an illusion of aristocracy and also prevents me from taking any small jobs." (56).

Nearly half the rural population in Bangladesh is landless (Saha 2002). Landless interviewees mentioned that the landed could use loans to further consolidate their wealth. Agricultural banks and NGO loans require land as collateral: "if we give them our land documents temporarily" (65). 
Thus, loans are not so easily accessible for the landless. Furthermore, they felt landowners could use their loans on economic activities rather than subsistence agriculture because they can grow their own food. This is supported by statements from land owners who avoid selling their land to maintain the subsistence security it confers. One farmer said, he "would no more sell his land than kill a crazy son" (48); meaning although agricultural activities are not always profitable, he would be reluctant to sell land.

Some respondents mention that a strong intra-community moral economy is breaking down: "Everyone is guided by his or her own judgement. All of us think why shall we be guided by others?" (41), but the role of large landowners as patrons to the poor continues. The poorest landless households, when in trouble, "seek help from other rich people. If we tell them that we're in big trouble, they help as much as they can" (42). Sometimes this assistance to the poor also takes the form of a place to stay, in return for work and political support: "Since we live on their land, we must do as they say" (45). Respected village members such as teachers and war veterans still play a role in mediator of disputes, even if the role of the informal village head has diminished $(56,5)$.

Seasonality remains a driving factor. The landless respondents described the wet season as the most difficult because reduced opportunities for agricultural labour combined with fewer off-farm activities and opportunities to buy food. One respondent said: "(We) have needs all year round-but the rainy season is the worst time for us... at that time we don't have work like loading-unloading [at the border with India]" (42). Another said: "Rainwater wets everything. They can't sow paddy and can't sell that" (57). Although there is a year-round shortage of opportunities for the landless: "Do your sons go outside for work?" "Of course. Otherwise what will we eat?" (57).

\subsubsection{Aquaculture}

Aquaculture ponds (ghers) can be used to cultivate shrimp, prawn, white fish, or rice (or a combination of them all) depending on the elevation of the plot, the salinity of surface water, access to irrigation, precipitation, and season. An economy exists supporting the ghers by collecting shrimp 
post-larvae from natural waters (31), providing fertiliser and other inputs such as snail meat (35), and delivering supplies to the pond owners $(7,8)$. This goes some way to remedying the loss of farm labouring opportunities, caused by low labour requirements on ghers, particularly shrimp farming (Swapan and Gavin 2011).

Aquaculture is associated with a loss of open-access resources. In brackish water shrimp areas, salinity precludes other ecosystem services. However, freshwater prawn can be cultivated in rotation with other crops, vegetables can be grown on pond walls, and there is sufficient plant life for animal fodder. Freshwater prawn cultivation is also associated with a loss of open-access wetland areas which has provided security of income for those with land but reduced open-access resources for the landless (5): "Earlier we had the freedom for fishing in the beel [a wetland], now we earn more [from aquaculture]"(32). Furthermore, nets used to collect the shrimp larvae to supply the ponds are perceived almost universally to have led to a decrease in fish stocks due to the by-catch. These nets are illegal but bans against them are not followed or well enforced.

Distinct differences can be observed between areas that are dominated by brackish shrimp aquaculture and areas that are dominated by freshwater prawn that, in turn, differ from those of farmers who concentrate solely on rice cultivation. Therefore, two different systems were defined, one for dominantly brackish shrimp cultivation, another for freshwater prawn dominated areas. The systems are separated based on: (i) forms of investment and issues of land rights, (ii) impacts on the poorest, and (iii) geographic location of the areas and associated stresses.

Forms of investment in, and access to, aquaculture practices differ. Expansion of brackish water shrimp aquaculture has been driven by external investors: "The owners of those large ghers were people coming from outside the area" (39). Thus, benefits tend to accrue outside the area to absentee landlords. Land conflicts arise, as rice farmers adjacent to shrimp areas have no choice but to convert to shrimp due to the negative effects of saline water intrusion on the productivity of their crops (see Faruque et al. 2017). In freshwater prawn areas, external investors and absentee landlords were not mentioned. What did arise in conversation were the large debts to set up the ponds for those who own land and different prices of land inside the polder (where cultivation can occur) and outside. 
The issues raised by the most marginalised households differ between the two systems. In brackish shrimp areas the poorer and landless respondents stated that their well-being would be improved by the return of a local landlord cultivating crops to whom they could go in emergences for food, loans, and help with medical costs (62). The return of agriculture would also provide bare subsistence for the ultra-poor: one destitute respondent mentioned that if there were still agriculture in the surrounding areas she could collect rice that had fallen to the ground during harvesting (9). More of the gher owners in the freshwater shrimp areas are owner-cultivators, and a wider range of crops can be cultivated (including through sharecropping opportunities), perhaps why such issues were not raised by respondents from this area.

Brackish shrimp areas are more remote from health services, markets, and alternative livelihood sources and more exposed to risks of storm surges and cyclones. However, they are also very close to the Sundarbans mangrove forest and the coast with easy access to offshore fisheries. This means that the poor are able to diversify into these alternative but precarious livelihoods of fishing, shrimp larvae collection, and forest collection. The case is different in the freshwater prawn areas; there are few open-access resources to support those without access to private property. Canals belong to the government or are on private land so the landless are unable to fish in them (35). Thus job opportunities are found in the nearby city of Khulna.

\subsubsection{Riverine Areas and Charlands}

Riverbank erosion occurs across the study area, often exacerbated by man-made river diversion or by malfunctioning systems of dykes and sluice gates due to siltation. By contrast in the eastern part of the delta, adjacent to the Meghna River, high levels of erosion and accretion lead to highly dynamic char islands. These stretches of land are, in effect, sandbanks in the river, attached to or detached from river banks, but with their own highly mobile and sometimes marginal populations.

The physical dynamics of chars has led to them being an important SES in their own right, recognised throughout the south Asian region 
and described as having "livelihoods defined by water" and populations living constantly with risk of displacement (Lahiri-Dutt and Samanta 2013). The principal characteristics of Charland SESs, as articulated by interview respondents, are (i) highly seasonal income and seasonal shifts in income between fishing and rain-fed agriculture, (ii) loss of land resulting in sudden changes in material well-being, (iii) high mobility of landless households, (iv) high reliance on richer patrons to help landless households, and (v) high insecurity of land tenure for those whose land has been submerged with the constant threat of land-grabbing.

The data from interviews with char dwellers reveal a high seasonality of income between crops in the wet season and fishing in the dry season. Cultivation is principally for subsistence. Charlands share characteristics common to agriculture and fisheries SESs. For example, sharecropping for the landless and mortgaging land to others when in financial difficulty and loans for fishing equipment that are paid back through a percentage of the profit on the catch.

Insecure land tenure was perceived by char dwellers as a critical issue in accessing ecosystem services. When land is eroded (and thus submerged) property rights remain with the owner if sediment accretes above the water level within 30 years. If not, the land returns to government ownership and can be redistributed to the landless. However, the interviewees mentioned that land can be appropriated by more influential people before it is reclaimed by the family (75), or names are changed on title deeds within government offices.

Associated with the constant erosion of riverbanks and islands is constant mobility. Households living on unclaimed strips of land on dykes and riverbanks find themselves continually moving as the riverbank erodes. In turn, constant mobility and the constant search for new land on which to build a household can create a dependence on wealthier neighbours and relations for support and patron-client relationships. One landless respondent who had been forced to move multiple times was able to generate income by raising cattle for a wealthier resident (73). Another respondent was allowed to live on a relative's land in return for work (75).

Loss of land is associated with change in livelihood. A person who has lost all their agricultural land to erosion must find alternative sources of income; respondents often mentioned that people become fishermen 
(e.g. 63). Loss of land through river erosion is also associated with a fall in income. When asked who were the poorest in the village, one respondent replied it was those who had lost their land to river erosion (27).

\subsubsection{Sundarban Mangrove Dependence}

This SES takes into account the people living directly adjacent to the Sundarbans mangrove forest. People fish on its margins and interior, and enter on a daily or weekly basis to collect firewood, honey, fish, crabs, and thatching among other resources. The Sundarbans is a nature reserve so people are prohibited from living within its boundaries. Households therefore live on its border among the brackish water shrimp ponds. Three themes emerged from the interviews with mangrove collectors: (i) highly seasonal incomes, (ii) high levels of livelihood and personal insecurity, and (iii) systems of permits that are difficult to navigate and/or ineffective.

Interviews with these natural resource users revealed livelihoods highly affected by seasonality. Wet season rains make collection of firewood difficult (9); in the dry season there is a scarcity of freshwater and people have to drink salty water (9); fishermen fish in different locations in different seasons $(8,14)$; resource collection is banned during certain periods (68); and the quality of resources (e.g. the size of crabs) changes with the season (11).

Some respondents move between different resource and day labour opportunities, while others exhibit extremely low livelihood mobility due to a strong livelihood-based identity (e.g. traditional fishermen), or a lack of human capital. For example, despite collection of firewood being prohibited, a woman of around 50 still went into the forest every day. In doing so, she faced the threat of both being detected and physical punished by forest guards as well as exposure to extreme weather and natural hazards (9).

This theme of insecurity commonly arose in interviews. Not just in terms of a stable income source but also in terms of the potential of physical harm from encounters with pirates, forest guards or wild animals, physically demanding working conditions, and the periodic threat of 
cyclones. This physical insecurity is partly a result of a lack of alternative livelihood sources outside the forest. One resource collector said: "You know in his heart nobody wants to go to the Sundarbans" because of fear (68). The loss of agriculture in the area to make way for shrimp ghers (described in Sect. 22.4.2) has removed a key alternative livelihood (10) increasing reliance on the forest resources to fill income gaps.

Another theme frequently occurring in this set of interviews is the system of permits and moratoriums on resource collection in the forest and the efficacy of the government forest regulators in enforcing them. Some interviewees collected wood despite it being illegal while others paid for the permits and respected periods when resource collection is prohibited. Respondents perceive a decrease in the quantity and diversity of fish catch and blame people using fine nets (14) as well as organised gangs collecting fish illegally in ways that are destructive to other species (e.g. poison-15). That is to say, because they perceive that, forest regulators are not enforcing rules effectively.

\subsubsection{Offshore Fisheries and the Coastal Periphery}

It is difficult to geographically define an SES based on fisheries. Reliance on local inland fisheries (in beels, canals, and rivers) is ubiquitous across the study area. People will also travel from inland areas to access offshore fishing activities. There are fishing villages (often majority Hindu), where fishing is a traditional livelihood and closely linked to identity, where men will fish from nearby rivers during the wet season, and offshore during the dry season; these villages can be found across the study area. Also, Sundarbans fishermen often live between the brackish shrimp ghers, and coastal fishermen live among agricultural land to take advantage of the subsistence agricultural opportunities it offers.

However, those living adjacent to the coast have easier access to the resources the ocean offers. Thus, this research defined a SES based on those areas with direct access to the Bay of Bengal. Three aspects of this system are commonly highlighted by interviewees: (i) seasonal livelihoods, (ii) the long-term recovery from Cyclone Sidr in 2009, and (iii) the role of debt relations in accessing fisheries. 
This SES is characterised by seasonal changes in livelihoods. Some fishermen alternative between species with different profitabilities: Hilsa (Tenualosa ilisha), in summer, and less profitable fish in other seasons or Hilsa in summer and shrimp post-larvae in the winter (31). Others alternate between livelihoods: one household collected forest resources from small patches of mangroves when food stores from subsistence agriculture were low (30).

Cyclone Sidr in 2009, and its continued impact on livelihoods, is a key feature for this system. People are still recovering from loss of assets and land damaged by salinity. One household had invested profits from fishing into cattle that were lost during Cyclone Sidr (54), a businessman lost his stock of dried fish that was on the beach when the cyclone hit (28).

Another key feature of this system is loans as a means to access fisheries. Loans are taken to access equipment, boats, and supplies, and are paid back as a proportion of the profit on the catch made. There is a more complex system for larger boats where groups of up to eight men travel offshore. These loans are accessed in advance per season and as a group through cooperation of the crew of the boat. Profits are subsequently apportioned to the crew and money lender $(29,68)$. These loans are associated with the accumulation of debt, and debt bondage as the catch is often insufficient to pay back the advance $(54,68)$.

However, while continuation of the loan system is not perceived as a positive aspect of household economies, some respondents felt there was no alternative (e.g. 29). Respondents also mentioned that loans have allowed people to access fisheries more easily as, whereas in the past men would wade off the beach up to their necks to catch fish, now they have boats, nets, and diesel and as such, access to more profitable species of fish that are found further offshore (29).

\subsection{Conclusion}

The timing and nature of ecosystem services across the study area give rise to different livelihood opportunities, means of access to ecosystem services, and coping mechanisms. This research demonstrates how these patterns of ecosystem service and human-environment interactions form 
seven distinct SESs. Each of these systems has, in effect, different barriers and enablers of access to ecosystem services and hence potential pathways out of poverty. The seven social-ecological systems demonstrate a large spatial range of ecosystem services as well as high variation throughout the year. Given the prevalence of diverse livelihoods by individuals and households described within these systems, this analysis suggests that policy interventions need to take account of that diversification and also be tailored to the dominant mechanisms and institutions within diverse social-ecological systems.

The research has highlighted that ecosystem service access is critical for subsistence of poor parts of delta populations across all the seven systems and that these ecosystem services are critical in poverty prevention for marginal sections of society. Yet there are potential trade-offs between ecosystem services and the need for subsistence and for finding routes out of poverty. Income from shrimp post-larvae collection, for example, is a key safety net for the poorest when they lose land or livelihoods. However, the collection of this shrimp has negative impacts on fish catch. Fishing communities retain solidarity and identity from the traditions and institutions of fishing. Yet with successive generations entering fishing, the resource is stressed. The situation is further complicated by the management of floods via sluice gates for the benefit of agriculture. This limits the ability of fish fry to enter the polder early in the breeding season, and thus maintain fish stocks.

Across all seven social-ecological systems highlighted here, some social trends and mechanisms are common. A crucial example is that the part of each population most directly connected to the ecosystem services are least able to benefit from, their presence. For fishers, for example, surplus accrues to the money lenders and traders. For landless labourers, profits accrue to landowners through rent or sharecropping. Hence, a common issue across all seven systems is to design mechanisms by which the poorest populations retain value and benefits as the ecosystem service travels up the commodity chain. Such interventions would be a significant step in enabling allowing ecosystem services to alleviate poverty and building the sustainability of the diverse social and ecological circumstances within delta regions. 


\section{Note}

1. http://reshare.ukdataservice.ac.uk/852356/

\section{References}

Adams, H., and W.N. Adger. 2016. Mechanisms and dynamics of wellbeingecosystem service links in the south-west coastal zone of Bangladesh. UK Data Service Reshare. https://doi.org/10.5255/UKDA-SN-852356, https://doi. org/10.5255/UKDA-SN-852356.

Adams, H., W.N. Adger, H. Huq, M. Rahman, and M. Salehin. 2013. Transformations in land use in the south-west coastal zone of Bangladesh: Resilience and reversibility under environmental change. Proceedings of Transformation in a Changing Climate International Conference, University of Oslo, Oslo.

Adams, H., W.N. Adger, S. Ahmad, A. Ahmed, D. Begum, A.N. Lázár, Z. Matthews, M.M. Rahman, and P.K. Streatfield. 2016. Spatial and temporal dynamics of multidimensional well-being, livelihoods and ecosystem services in coastal Bangladesh. Scientific Data 3: 160094. https://doi.org/ 10.1038/sdata.2016.94.

Allison, E.H., and F. Ellis. 2001. The livelihoods approach and management of small-scale fisheries. Marine Policy 25 (5):377-388. https://doi.org/10.1016/ S0308-597X(01)00023-9.

Barbier, E.B., S.D. Hacker, C. Kennedy, E.W. Koch, A.C. Stier, and B.R. Silliman. 2011. The value of estuarine and coastal ecosystem services. Ecological Monographs 81 (2): 169-193. https://doi.org/10.1890/10-1510.1.

Cinner, J.E., T.M. Daw, T.R. McClanahan, N. Muthiga, C. Abunge, S. Hamed, B. Mwaka, A. Rabearisoa, A. Wamukota, E. Fisher, and N. Jiddawi. 2012. Transitions toward co-management: The process of marine resource management devolution in three east African countries. Global Environmental Change 22 (3): 651-658. https://doi.org/10.1016/j.gloenvcha.2012.03.002. Cote, M., and A.J. Nightingale. 2012. Resilience thinking meets social theory: Situating social change in socio-ecological systems (SES) research. Progress in Human Geography 36 (4): 475-489. https://doi.org/10.1177/ 0309132511425708. 
Crane, T.A. 2010. Of models and meanings: Cultural resilience in socioecological systems. Ecology and Society 15 (4): 19. www.ecologyandsociety. org/vol15/iss4/art19/.

Davis, P. 2009. Poverty in time: Exploring poverty dynamics from life history interviews in Bangladesh. In Poverty dynamics: Interdisciplinary perspectives, ed. T. Addison, D. Hulme, and R. Kanbur, 154-182. Oxford: Oxford University Press.

De Aranzabal, I., M.F. Schmitz, P. Aquilera, and F.D. Pineda. 2008. Modelling of landscape changes derived from the dynamics of socio-ecological systems A case of study in a semiarid Mediterranean landscape. Ecological Indicators 8 (5): 672-685. https://doi.org/10.1016/j.ecolind.2007.11.003.

Fabinyi, M., L. Evans, and S.J. Foale. 2014. Social-ecological systems, social diversity, and power: Insights from anthropology and political ecology. Ecology and Society 19 (4): 28. https://doi.org/10.5751/ES-07029-190428.

Faruque, G., R.H. Sarwer, M. Karim, M. Phillips, W.J. Collis, B. Belton, and L. Kassam. 2017. The evolution of aquatic agricultural systems in Southwest Bangladesh in response to salinity and other drivers of change. International Journal of Agricultural Sustainability 15 (2): 185-207. https://doi.org/10.108 0/14735903.2016.1193424.

Hill, R., C. Grant, M. George, C.J. Robinson, S. Jackson, and N. Abel. 2012. A typology of indigenous engagement in Australian environmental management: Implications for knowledge integration and social-ecological system sustainability. Ecology and Society 17 (1): 23. https://doi.org/10.5751/ es-04587-170123.

Karpouzoglou, T., A. Dewulf, and J. Clark. 2016. Advancing adaptive governance of social-ecological systems through theoretical multiplicity. Environmental Science and Policy 57: 1-9. https://doi.org/10.1016/j. envsci.2015.11.011.

Lahiri-Dutt, K., and G. Samanta. 2013. Dancing with the river: People and life on the chars of South Asia. New Haven: Yale University Press.

Levin, P.S., M.J. Fogarty, S.A. Murawski, and D. Fluharty. 2009. Integrated ecosystem assessments: Developing the scientific basis for ecosystem-based management of the ocean. PLoS Biology 7 (1): 23-28. https://doi.org/10.1371/ journal.pbio. 1000014 .

Nagendra, H., and E. Ostrom. 2014. Applying the social-ecological system framework to the diagnosis of urban lake commons in Bangalore, India. Ecology and Society 19 (2): 67. https://doi.org/10.5751/es-06582-190267.

Ostrom, E. 1990. Governing the commons: The evolution of institutions for collective action. Cambridge: Cambridge University Press. 
Rodriguez, J.P., T.D. Beard, E.M. Bennett, G.S. Cumming, S.J. Cork, J. Agard, A.P. Dobson, and G.D. Peterson. 2006. Trade-offs across space, time, and ecosystem services. Ecology and Society 11 (1): 28. www.ecologyandsociety. org/vol11/iss1/art28/.

Saha, B.K. 2002. Rural development trends: What the statistics say. In Hands not land: How livelihoods are changing in rural Bangladesh, ed. K.A. Toufique and C. Turton. Dhaka: Bangladesh Institute of Development Studies, Dhaka and Department for International Development, London.

Swapan, M.S.H., and M. Gavin. 2011. A desert in the delta: Participatory assessment of changing livelihoods induced by commercial shrimp farming in Southwest Bangladesh. Ocean and Coastal Management 54 (1): 45-54. https://doi.org/10.1016/j.ocecoaman.2010.10.011.

Tourfique, K.A. 2002. Agricultural and non-agricultural livelihoods in rural Bangladesh: A relationship in flux. In Hands not land: How livelihoods are changing in rural Bangladesh, ed. K.A. Toufique and C. Turton. Dhaka: Bangladesh Institute of Development Studies, Dhaka and Department for International Development, London.

Wood, G. 2003. Staying secure, staying poor: The "Faustian bargain". World Development 31 (3): 455-471. https://doi.org/10.1016/s0305-750x(02) 00213-9.

Open Access This chapter is licensed under the terms of the Creative Commons Attribution 4.0 International License (http://creativecommons.org/ licenses/by/4.0/), which permits use, sharing, adaptation, distribution and reproduction in any medium or format, as long as you give appropriate credit to the original author(s) and the source, provide a link to the Creative Commons license and indicate if changes were made.

The images or other third party material in this chapter are included in the chapter's Creative Commons license, unless indicated otherwise in a credit line to the material. If material is not included in the chapter's Creative Commons license and your intended use is not permitted by statutory regulation or exceeds the permitted use, you will need to obtain permission directly from the copyright holder.

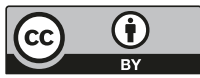

